Research Paper

\title{
Sensitization of Carboplatinum- and Taxol-Resistant High-Grade Serous Ovarian Cancer Cells Carrying p53, BRCA1/2 Mutations by Emblica officinalis (Amla) via Multiple Targets
}

\author{
Alok De ${ }^{\bowtie}$, Archana De, Ramratan Sharma, William Suo and Mukut Sharma \\ Kansas City VA Medical Center and Midwest Veterans Biomedical Research Foundation, Kansas City, MO 64128, USA \\ $\bowtie$ Corresponding author: Alok De: Alok.De@va.gov, alokde2001@yahoo.com
}

(c) The author(s). This is an open access article distributed under the terms of the Creative Commons Attribution License (https://creativecommons.org/licenses/by/4.0/). See http://ivyspring.com/terms for full terms and conditions.

Received: 2019.10.13; Accepted: 2019.12.01; Published: 2020.01.29

\begin{abstract}
Background: Ovarian cancer (OC), the most lethal gynecologic malignancy, is highly resistant to current treatment strategies. High-grade serous epithelial ovarian cancer (HGSOC) cells with increased somatic mutations and genomic instability and the resulting heterogeneous mutant phenotypes are highly resistant to therapy. Plant-derived natural products, including Amla (Emblica officinalis) extract (AE), have demonstrated potent anti-neoplastic properties. Recently we demonstrated that $A E$ inhibits cell growth and the expression of angiogenic factors in OVCAR3 and SKOV3 OC cells in vitro as well as in xenografts in vivo. The goal of this study was to determine the anti-proliferative, anti-angiogenic and anti-metastatic effects of AE on carboplatinum- and taxol-resistant HGSOC cells carrying P53, BRCA1/2 mutations.

Methods: Anti-proliferative and anti-metastatic effects of $\mathrm{AE}$ on recently characterized carboplatinum- and taxol-resistant HGSOC cells (TOV3041G, OV866(2), OV4453 and, OV4485) was determined using the MTT, migration, invasion and spheroid assays in vitro. To understand the mechanism of $A E$-induced changes in angiogenesis-related hypoxia-inducible factor $1 \alpha$ (HIF-l $\alpha$ ) and insulin growth factor receptor 1 (IGFIR), and EMT-associated SNAILI and E-cadherin proteins were studied using immunostaining and Western blotting. In vivo effects of $A E$ were determined using mouse xenograft tumor model of $O C$ developed by subcutaneous injection of OV4485 cells that carry mutant p53 and BRCA1, most aggressive and resistant among HGSOC cell lines used in this study. Tumor growth was measured using morphometry. Immunostaining and Western blotting were used to determine changes in Ki67 (proliferation marker), CD31 (angiogenesis marker) as well as changes in HIF-1a, IGFIR, SNAILI and E-cadherin proteins.

Results: AE significantly attenuated migration and invasiveness properties of all tested HGSOC cell phenotypes ( $P \leq 0.001$ ), significantly reduced the expression of HIF-1 $\alpha$, IGFIR, and SNAILI and increased the expression of $\mathrm{E}$-cadherin in all tested HGSOC cell lines $(\mathrm{P}=<0.05)$. Oral administration of $\mathrm{AE}$ for 4 weeks caused a significant regression of mouse xenograft tumor $(>60 \%)$ that derived from OV4855 cells and decreased the expression of endothelial cell antigen-CD31, HIF-Ia, IGFIR and SNAILI and increased the expression of E-cadherin in tumor tissues.

Conclusions: $A E$ sensitizes platinum- and taxol-resistant heterogenous HGSOC cells carrying mutations in $\mathrm{p} 53, \mathrm{BRCA} 1 / 2$ genes, and attenuates their malignant characteristics through targeting key signaling mechanisms of angiogenesis and metastasis. AE is a potential adjunct therapeutic agent for treating resistant, mutant, heterogenous OC.
\end{abstract}

Key words: high-grade serous ovarian cancer, Amla, resistant, angiogenesis, metastasis, sensitize, mutation

\section{Background}

Ovarian cancer (OC) is the fifth leading cause of cancer-related deaths and accounts for more deaths than any other cancer of the female reproductive system. OC often escapes early diagnosis and 
develops resistance to treatment resulting in poor prognosis that is closely associated with origins of the cancer [1]. Resistant high-grade serous ovarian cancers (HGSOC) are aggressive and resistant to current therapies and are sustained by a microenvironment that promotes angiogenesis [2]. Multiple genetic and epigenetic modifications as well as epithelial-to-mesenchymal transition (EMT) augment the survival, growth and metastasis of aggressive HGSOC [3]. Specifically, angiogenesis is potentiated by hypoxia which is a common characteristic of many aggressive carcinomas [4]. Hypoxia-inducible factor 1a (HIF-1a), a transcription factor, is a key mediator of tumorigenesis through activation of genes associated with angiogenesis and metastasis. Over-expression of HIF-1a is associated with invasive phenotypes and aggressive nature of $\mathrm{OC}$ cells and poor survival of patients with OC [5]. Hypoxia induces HIF-1a and insulin-like growth factor 1 receptor (IGF1R) that independently or together induce growth, transformation, metastasis and angiogenesis [6]. High rate of metastasis observed in OC begins with EMT, a critically significant process in invasive cancers [7]. EMT activates a zinc finger protein transcription factor named SNAIL1 that promotes the invasive nature of human OC cells through downregulation of E-cadherin [8]. These distinct but interconnected processes drive the growth and spread of resistant cancer. Simultaneous attenuation of these factors may be the key to minimize the aggressive nature of cancer cells.OC is characterized by a variety of mutations and heterogeneity that add to its resistant nature [9-13]. Therefore, novel therapeutic approaches are needed to simultaneously target processes such as angiogenesis and EMT for an effective control of resistant cancer cells with diverse phenotypic characteristics. Adjunct agents that modulate multiple cellular processes may improve the efficacy of current therapeutic agents and overall clinical outcomes. Plant-derived products are known to have anti-tumor effects with low toxicity [14]. A plant-derived compound has been shown to decrease mutation rate in tissues exposed to mutagen [15]. In addition to its antioxidant effects, Amla (Emblica officinalis) (fruit, leaves, bark, root) extract (AE) has anti-neoplastic properties [14] and inhibits the proliferation of a variety of cancer cells in vitro including OC cells [14], prevents DNA damage induced by carcinogens and mutagens [14] and causes tumor regression in mouse xenograft model $[14,16,17]$.

The objective of the present study was to determine whether AE can sensitize highly aggressive, mutant, metastatic and resistant heterogenous HGSOC cell lines (Table 1) with mutations in multiple genes [11]. Our results show that treatment with $\mathrm{AE}$ attenuated proliferation, migration and invasiveness properties of all tested HGSOC cell phenotypes in vitro and caused $>60 \%$ decrease in xenograft tumor size in vivo.

\section{Materials and Methods}

\section{Ethical Statement}

All animals were maintained according to standard guidelines of the American Association for the Accreditation of Laboratory Animal Care. The study was approved by the Institutional Animal Care and Use Committee of the Kansas City VA Medical Center (Kansas City, MO). Research described hereunder was conducted in agreement with ethical standards according to the Declaration of Helsinki, National and International guidelines.

\section{Cell culture and reagents}

Dr. Mes-Messon, Montreal, Canada kindly gifted all HGSOC cell lines used in this study. As shown in Table 1 these HGSOC cell lines (i) are heterogenous, (ii) have a variety of different and important characteristics of the HGSOC disease in which p53 gene is non-functional - either mutated or silenced, (iii) do not harbor somatic mutations in KRAS, BRAF, ARIDIA, CTNNB1 or PIK3CA that have been previously shown to associate with low serous epithelial cells (29), and (iv) do not show high expression of HER2. These cells were recently characterized and, OV4485 are reportedly the most aggressive among these cell lines [11]. Cells were maintained in ovarian surface epithelial Medium (OSEM, Wisent Bioproducts, Quebec, Canada) supplemented with 10\% fetal bovine serum (ThermoFisher Scientific, Waltham, MA, USA) and penicillin-streptomycin (complete OSEM) at $37^{\circ} \mathrm{C}$ in $5 \%$ carbon dioxide and $7 \%$ oxygen. AE stock solution was prepared by dissolving $\mathrm{AE}$ tablets (Himalaya USA, Sugarland, TX) in endotoxin free sterile water $(10 \mathrm{mg} / \mathrm{mL})$ and filtering through a 0.22 $\mu \mathrm{m}$ cellulose acetate membrane $[16,17]$.

\section{Treatment}

TOV3041G, OV866(2), OV4453 and OV4485 cells $(9,000$ cells/well in $100 \mu 1$ in 96 well plate) or $(50,000$ cells/well in $1 \mathrm{ml}$ of 24-well plates) in complete OSEM were treated with $\mathrm{AE}(0-800 \mu \mathrm{g} / \mathrm{ml}$; each in triplicates) for $24-96$ hours at $37^{\circ} \mathrm{C}$.

\section{Cell proliferation}

Cell proliferation was assessed using [3-(4,5-dimethylthiazol-2-yl)-2,5-diphenyltetrazolium bromide)] (MTT) assay. Control and treated cells were incubated with MTT (0.1 mg/well, Millipore-Sigma) for $4 \mathrm{~h}$ at $37^{\circ} \mathrm{C}$. The formazan crystals formed were solubilized in isopropanol $(100 \mu \mathrm{l})$ and optical density 
was measured at $560 \mathrm{nM}$. The number of functionally active cells was calculated from optical density values for untreated and treated groups. Results are presented as \pm standard error means $( \pm$ SEM) of six experiments performed in duplicates for each treatment condition.

\section{Invasion assay}

Cells $\left(7 \times 10^{4} /\right.$ well $)$ suspended in serum-free OSEM $(250 \mu \mathrm{l})$ were layered on 24- Transwell (Corning ${ }^{\circledR}, \mathrm{NY}$, USA) permeable support membranes pre-coated with Matrigel matrix (100 $\mu \mathrm{l} /$ well, Corning ${ }^{\circledR}$, NY, USA). Complete OSEM alone or complete OSEM (600 $\mu \mathrm{l} /$ well) containing AE (400-500 $\mu \mathrm{g} / \mathrm{ml}$ ) was added to wells. Preliminary work showed that OV866(2) moved faster and OV4485 cells moved slower than other cells. Therefore, OV866(2) cells were fixed at $6 \mathrm{~h}$ and OV4485 cells at $24 \mathrm{~h}$ in cold $100 \%$ methanol, stained with $0.1 \%$ crystal violet and photographed. For quantitative analysis of cell migration, five randomly chosen different areas of crystal violet-stained cells were counted. Results are presented as the number of cells \pm SEM of three experiments performed in duplicates for each treatment condition.

\section{Spheroid assay}

Previously described spheroid assay was used to determine the effect of AE on the ability of HGSOC cells to loosen aggregates of spheroid structures [11]. Briefly, 4,000 cells were suspended in $16 \mu \mathrm{l}$ of complete OSEM with or without AE $(400 \mu \mathrm{g} / \mathrm{ml}$ for all cell lines and $500 \mu \mathrm{g} / \mathrm{ml}$ for OV4485 cell line) and placed on the lid of tissue culture petri dishes. Spheroid formation was assessed after 7 days of incubation in $7 \% \mathrm{O}_{2}, 5 \% \mathrm{CO}_{2}$ at $37^{\circ} \mathrm{C}$. This experiment was repeated four times.

\section{Migration assay}

Scratch wounds were made to $80-90 \%$ confluent TOV3041G, OV866(2), OV4453 or OV4485 cells, treated with AE $(0-800 \mu \mathrm{g} / \mathrm{ml})$ and scratched areas were photographed at $0,6,24$ and $48 \mathrm{~h}$ using EVOS XL Core Cell Imaging System (ThermoFisher Scientific). Since OV4485 cells migrate slowly,these cells were treated up to $72 \mathrm{~h}$ and photographed at $0,24,48$ and $72 \mathrm{~h}$. The relative migration gap distance was calculated using the equation: the relative migration distance $(\%)=100(\mathrm{~A}-\mathrm{B}) / \mathrm{A}$, where $\mathrm{A}$ and $\mathrm{B}$ are the widths of the scratch area before and after incubation, respectively. Results are shown as mean relative migration gap \pm SEM. from six independent experiments.

\section{Immuno-staining}

HGSOC cells and xenograft tumors were fixed in
$4 \%$ buffered formaldehyde ( $\mathrm{pH}$ 7.4). Cells and tissue sections were incubated with 1:100 diluted antibodies to HIF-1a, SNAIL1, E-cadherin (Cell Signaling Technology, Boston, MA, USA) or IGF1R (EMD Millipore, Billerica, MA, USA) overnight at $4^{\circ} \mathrm{C}$. Immuno-staining was performed using ImmPRESS HRP reagent kit (Vector Laboratories, Burlingame, CA, USA). Cells and tissue sections were counterstained with hematoxylin. A Leica digital microscope was used for imaging to determine the percent immuno-stained cells (immuno-stained cells/total number of cells $\times 100)$. Two investigators, blinded to sample-source, independently counted immuno-stained cells. Cells and tissue sections were first examined at $5 x$ magnification to identify immuno-positive regions in cultured cells and tumor sections. Five different areas of cultured cells and tumor sections were selected at random and evaluated microscopically at a 40x objective magnification. Immuno-stained cells and total cells were counted and the percentage of cells with immunolabeling was calculated. Cultured cells from four independent experiments were used. For tissue immuno-staining five mice were used in each group.

\section{Western blotting}

Ten microgram total protein was used for SDS-PAGE followed by electro-transfer to a nitrocellulose membrane. The membrane was incubated overnight at $4^{\circ} \mathrm{C}$ with 1:1000 diluted primary antibodies to HIF-1a, SNAIL1, E-cadherin or IGF1R. Anti $\beta$-actin 1:10000 dilution (Abcam) was used as loading control. The membrane was then incubated with 1:10000 diluted HRP-conjugated secondary antibodies (Millipore-Sigma) at room temperature for $1 \mathrm{~h}$. Immunoreactivity was detected using enhanced chemiluminescence reagent (GE Healthcare Bio-Sciences, Marlborough, MA). The results are presented as mean \pm SEM of three experiments. $\beta$-actin was used as the loading control.

\section{Xenograft tumor studies}

Nude mice (nu/nu genotype, Harlan Laboratories, Madison, WI) were maintained at the AAALAC accredited Animal Care Facility of KC VAMC. Eight-week-old nude mice were maintained on water and food ad libitum in a pathogen free environment with a $12 \mathrm{~h}$ light and $12 \mathrm{~h}$ dark cycle. In previous in vivo studies we used OVCAR3 and SKOV3 cells. These cells are now considered less aggressive. OVCAR3 cells express the R248Q mutant p53 and SKOV3 cells do not express p53 protein or mRNA (29). In the present studies we intended to determine whether AE has any effect on xenograft tumor derived from resistant/aggressive cells with 
mutation(s) in different/additional genes (e.g. BRCA). Therefore, we used OV4485 cells which is a BRCA1 mutated cell line resistance to carboplatinum (Table 1 ). Fleury et al showed rapid growth of tumors derived from OV4485 cells and poor survival of mice compared to tumors developed from BRCA2 mutated OV4453 cells [13]. OV4485 cells $\left(5 \times 10^{6}\right)$ with Matrigel (1:1 ratio volume) were injected subcutaneously into the right rear flanks of eight weeks old female mice. Mice were monitored every day for tumor mass that was visible at 2 months after cell injection. Once the tumor mass was visible, mice were randomly divided into two groups: control and treated. Treatment group received $\mathrm{AE}(100 \mathrm{mg} / \mathrm{kg}$ body weight/day in $10 \%$ sucrose) during night time only as described previously [16, 17]. Control group received 10\% sucrose solution only during night time. Mice were weighed twice/week. Tumor size was measured with digital caliper once every week and volume calculated using the formula: tumor volume $=$ length $\mathrm{x}$ width $\mathrm{x}$ 0.5 width. After 4 weeks of AE treatment mice were euthanized. Tumors were removed and processed for analysis (immunohistochemistry and Western blotting). Five mice in each group (control and treated) were used based on our previous experience $[11,12]$. No adverse effect was noted due to $\mathrm{AE}$ treatment.

\section{Statistical analysis}

All experiments were conducted for three replicates. All data are expressed as the mean \pm standard error means (SEM). Significance was tested using unpaired, two-tailed Student's t-Test with unequal variance and ANOVA with Bonferroni post hoc test. $\mathrm{P} \leq 0.05$ was considered significant.

\section{Results}

\section{AE attenuated the proliferation of HGSOC cells in a dose- and time-dependent manner}

TOV3041G (non-mutated, resistant), OV866(2) (TP53 mutation, resistant), OV4453 (TP53, BRCA2, CSMD3 and RB1 mutations, resistant) and OV4485 (TP53 and BRCA1 mutations, resistant) were cultured as outlined under Methods and were treated with AE $(100-800 \mu \mathrm{g} / \mathrm{ml})$ for $24-96$ hours to assess cell proliferation and viability using the MTT assay.

$\mathrm{AE}$ inhibited the proliferation of all cell lines in a dose- and time-dependent manner. At 24 hours, lower concentrations of $\operatorname{AE}(100 \mu \mathrm{g} / \mathrm{ml}$ and $200 \mu \mathrm{g} / \mathrm{ml})$ caused $20-30 \%$ inhibition of cell proliferation of TOV3041G, OV866(2) and OV4453 (Fig. 1A-C) (but not OV4485 cells) compared to untreated control cells (Fig. 1D). Half maximal dose for three cell lines at $48 \mathrm{~h}$ was $400 \mu \mathrm{g} / \mathrm{ml}$ except OV4485 that required 500 $\mu \mathrm{g} / \mathrm{ml}$ for half maximal effect (Fig. 1A-D). Higher doses of AE $(500-800 \mu \mathrm{g} / \mathrm{ml})$ caused significant inhibition at 24-96 h. These results suggest that $\mathrm{AE}$ has anti-proliferative effect on resistant, mutated, heterogenous HGSOC cells and that BRCA1 mutated OV4485 cells (isolated after carboplatin/taxol treatment, Table 1) required higher dose of $\mathrm{AE}$ and for longer duration.

\section{AE inhibited malignant properties (invasiveness, spheroid formation and migration) of HGSOC cells in vitro}

Invasive/aggressive cells constitute one of the characteristics of cancer metastasis [18]. Therefore, we compared the effect of $\mathrm{AE}$ on invasiveness of OV866(2) and OV4485 cells by the invasion assay using Transwells. AE treatment attenuated the invasiveness of OV866(2) cells $(\mathrm{P}=0.02)$ at 6 hours and OV4485 cells $(\mathrm{P}=0.01)$ at 24 hours (Fig. 1 E-H) highlighting the potent effect of $\mathrm{AE}$ on cells with differences in mutations and invasiveness.

Spheroid formation represents one of the major three-dimensional (3D) in vitro models for cancer studies that serve as an intermediate approach between in vitro cancer cell line cultures and in vivo tumors [19]. Therefore, we studied spheroid formed by TOV3041G, OV866(2), OV4453 and OV4485 cells and found that spheroid formed by these cells were compact (Fig. 1I-L). AE treatment loosened the spheroids formed by each of the tested HGSOC cell line (Fig. 1I-L). These results suggest that AE inhibits the formation of compact spheroid by HGSOC cells.

Table 1. Characteristics of various HGSOC cells used.

\begin{tabular}{|c|c|c|c|c|}
\hline Cell name & Histopathological sub-type & Origin & Characteristics & Resistance \\
\hline TOV3041G & Human high- grade serous & Tissue & No predicted deleterious mutation identified & $\begin{array}{l}\text { Isolated after Carboplatin/taxol, } \\
\text { cisplatin/taxol treatment }\end{array}$ \\
\hline OV866(2) & Human high-grade serous & Serous & TP53 mutant [-c 745 A > T (R249W) & Isolated after Carboplatin/taxol treatment \\
\hline OV4453 & Human high-grade serous & Serous & $\begin{array}{l}\text { TP53 mutant [c375-1 G>A (splice), BRCA2 mutant [c } 5857 \\
\text { G>T (E1953X), CSMD3 mutant (c 1937 G>C (S646T)] , RB1 } \\
\text { mutant [c 2490-5_2490-1 del5 (splice)] }\end{array}$ & Isolated before chemotherapy treatment \\
\hline OV4485 & Human high-grade serous & Serous & $\begin{array}{l}\text { TP53 mutant [c } 818 \text { G>A (R273H), BRCA1 mutant [c } 4485-1 \\
\text { G>T (splice). }\end{array}$ & Isolated after Carboplatin/taxol treatment \\
\hline \multicolumn{5}{|c|}{$\begin{array}{l}\text { Note: Heterogeneous cell lines of serous or tissue origin used for present studies were previously characterized by Fleury et al (2015). Specifically, OV4485 cells were isolate } \\
\text { after carboplatin/taxol treatment while comparable OV } 4453 \text { were isolated prior to chemotherapy. OV4485 carrying TP53 and BRCA1 mutations were found to be most } \\
\text { aggressive (Fleury et al. 2015). Present in vitro studies also indicated highly aggressive and resistant nature of OV4485 cells (see Results and Discussion sections). OV4485 } \\
\text { were selected as a representative resistant cell line for in vivo xenograft studies. }\end{array}$} \\
\hline
\end{tabular}


Cell proliferation

A.

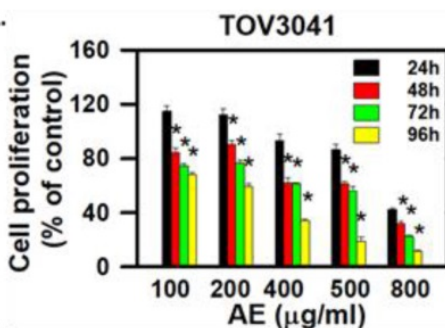

c.
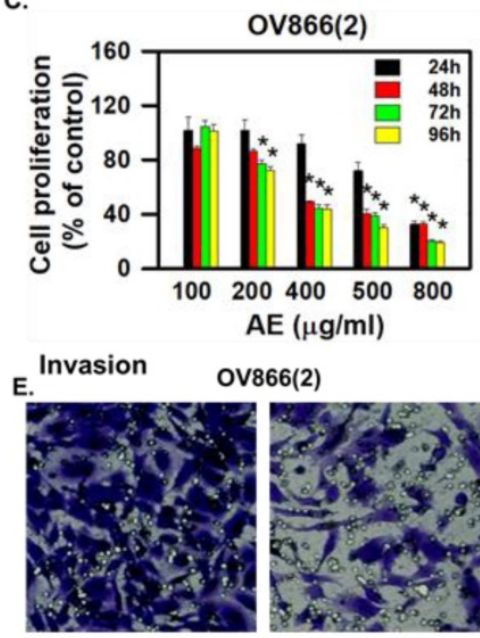

Ctrl

F.

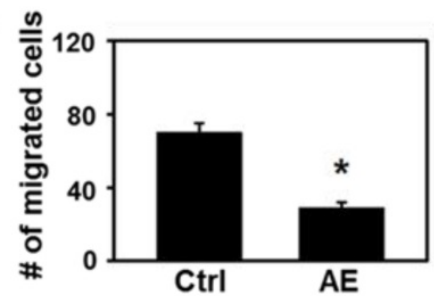

\section{Spheroid formation}
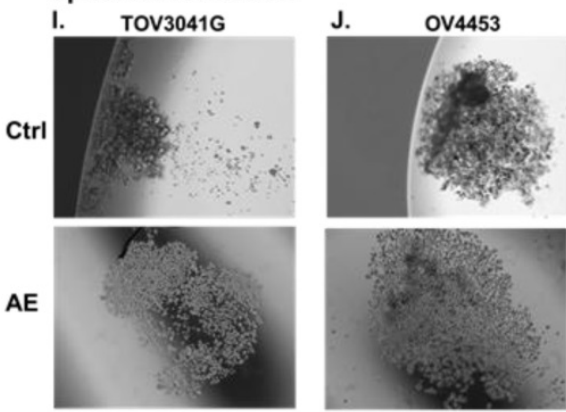

B.

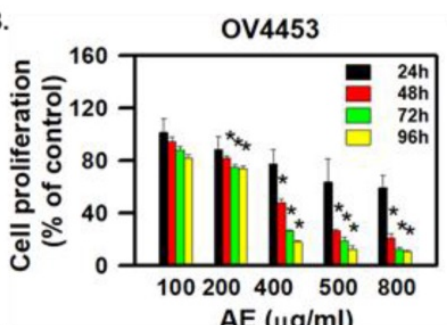

D.

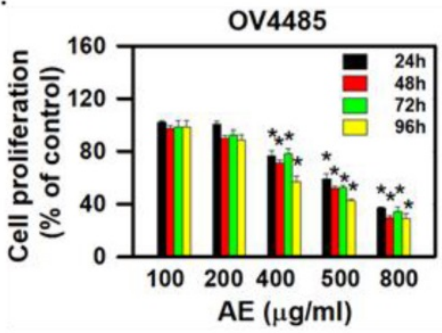

G.

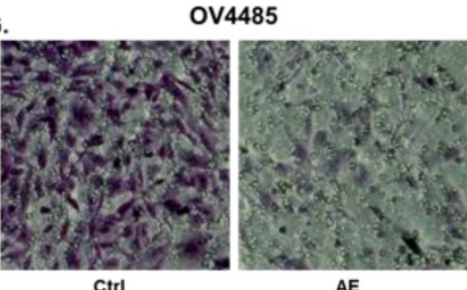

H.

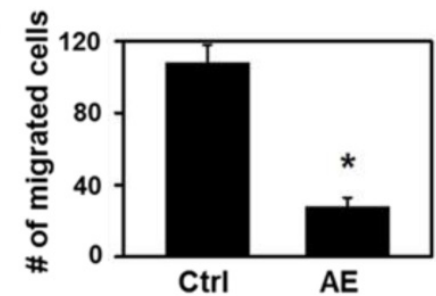

K.

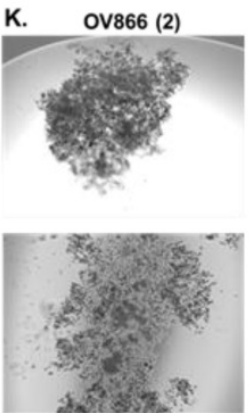

L. $\quad 0$ 4485
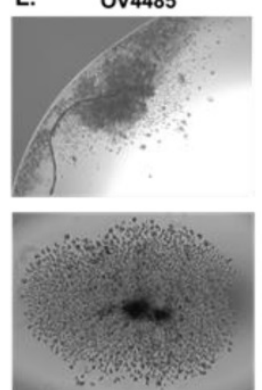

Figure 1. AE treatment inhibited cell proliferation, invasiveness and spheroid formation in highly aggressive, resistant, metastatic mutant high-grade serous ovarian cancer cells. (A-D) Time- and dose- dependent effects of AE on proliferation of (A) TOV3041, (B) OV4453, (C) OV866(2) and (D) OV4485 cells. Cells were treated with different doses of AE for 24-96 hours as shown and proliferation was assesses using the MTT assay. Results are presented as percent of untreated control cells (mean + S.E.M, $n=6$ independent observations, * $P<0.05)$. (E-H) AE inhibited invasiveness of OV866(2) and OV4485 cells. (E-F) AE (400 $\mu \mathrm{g} / \mathrm{ml})$ inhibited the invasiveness of OV866(2) after incubation for $6 \mathrm{~h}$ and (G-H) AE $(500 \mu \mathrm{g} / \mathrm{ml})$ inhibited the invasiveness of OV4485 cells for $24 \mathrm{~h}$ determined using the Transwell assay. Representative images (20x magnification) show OV866(2) and OV4485 cells that crossed to the basal side of the membrane indicating invasiveness. (F, H) Number of migrated cells from randomly chosen five areas of crystal violet-stained cells (mean + SEM of 3 independent experiments each in duplicate. *, P $\leq 0.05$ compared with control). (I-L) AE decreased the formation of compact spheroid formation by TOV3041G, OV866(2), OV4453 and OV4485 cells. Representative images show loosened spheroids after $A E$ treatment. $C=$ control, AE=Amla extract.

Cell migration is another major characteristic of metastasis [18]. Therefore, we studied the effect of AE on migration of TOV3041G, OV866(2), OV4453 and OV4485 cells using the scratch wound healing assay. Our results show that $\mathrm{AE}$ at lower concentration partially inhibited migration (Fig. 2A, C, E, G) and this effect of AE on migration of TOV3041G, OV866 (2), OV4453 and OV4485 cells varied in dose- and time-dependent manner. A comparison of relative gap distances after AE treatment is shown in Fig. 2B, 
D, F, H).

Migration of TOV3041 cells was not affected by any concentration of AE for $6 \mathrm{~h}$ but only $800 \mu \mathrm{g} / \mathrm{ml}$ AE significantly inhibited migration after $24 \mathrm{~h}$ of incubation ( $\mathrm{P}=0.003)$. AE at $400 \mu \mathrm{g} / \mathrm{ml}, 500 \mu \mathrm{g} / \mathrm{ml}$ and $800 \mu \mathrm{g} / \mathrm{ml}$ significantly $(\mathrm{P}=0.013, \mathrm{P}=0.002$ and $\mathrm{P} \leq 0.001$, respectively) inhibited migration at $48 \mathrm{~h}$ incubation (Fig. 2A and B).

Migration of OV4453 cells remained unaffected

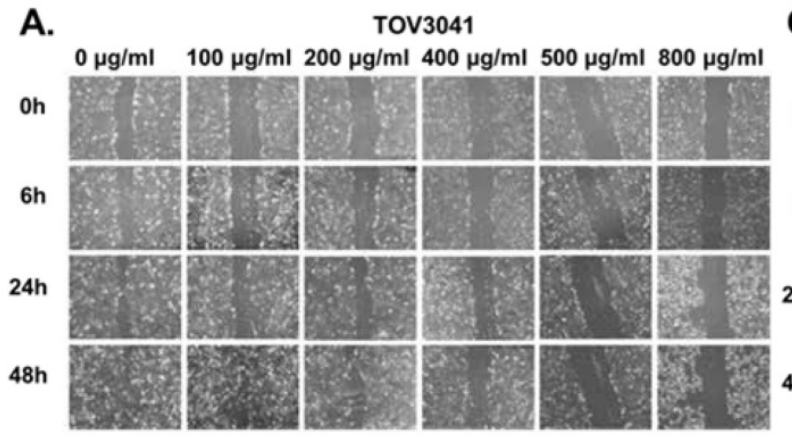

B.

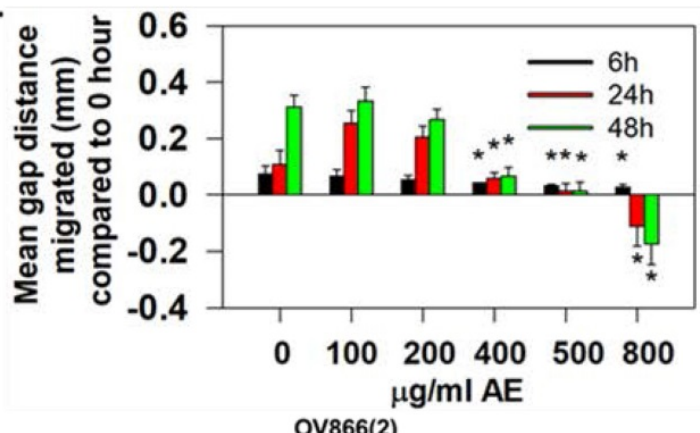

E. $0 \mu \mathrm{g} / \mathrm{ml} \quad 100 \mu \mathrm{gg} / \mathrm{ml} 200 \mu \mathrm{\mu g} / \mathrm{ml} 400 \mu \mathrm{g} / \mathrm{ml} 500 \mu \mathrm{gg} / \mathrm{ml} 800 \mu \mathrm{\mu g} / \mathrm{ml}$

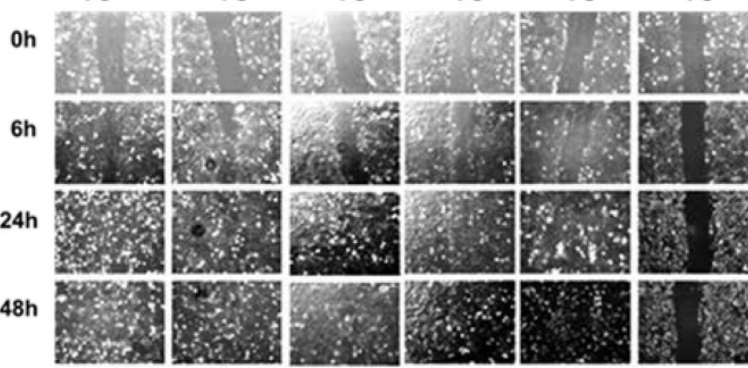

F.

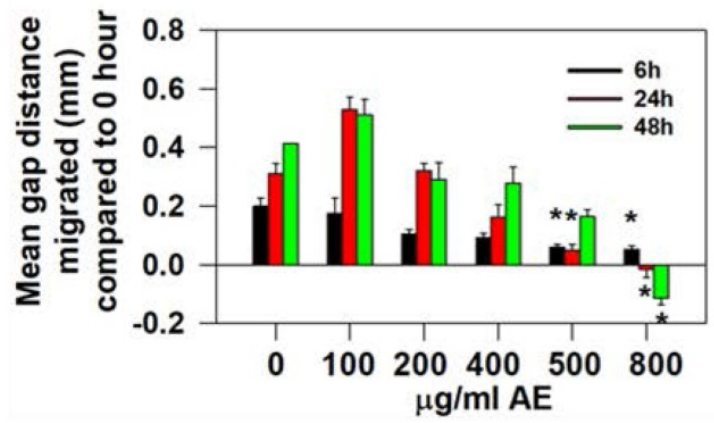

by all concentrations of $\mathrm{AE}$ at $6 \mathrm{~h}$ and $24 \mathrm{~h}$. AE at $200-800 \mu \mathrm{g} / \mathrm{ml}$ caused significant inhibition $(\mathrm{P} \leq 0.001)$ of migration at $48 \mathrm{~h}$ incubation (Fig. 2C and D).

Migration of OV866(2) was affected only at AE concentrations of $500 \mu \mathrm{g} / \mathrm{ml}(\mathrm{P}=0.02)$ and $800 \mu \mathrm{g} / \mathrm{ml}$ $(\mathrm{P}=0.002)$ by $6 \mathrm{~h}$. $\mathrm{AE}$ at $800 \mu \mathrm{g} / \mathrm{ml}$ significantly $(\mathrm{P} \leq 0.001)$ blocked the migration at $24 \mathrm{~h}$ and $48 \mathrm{~h}$ (Fig. 2E and $\mathbf{F}$ ).

C.

OV4453

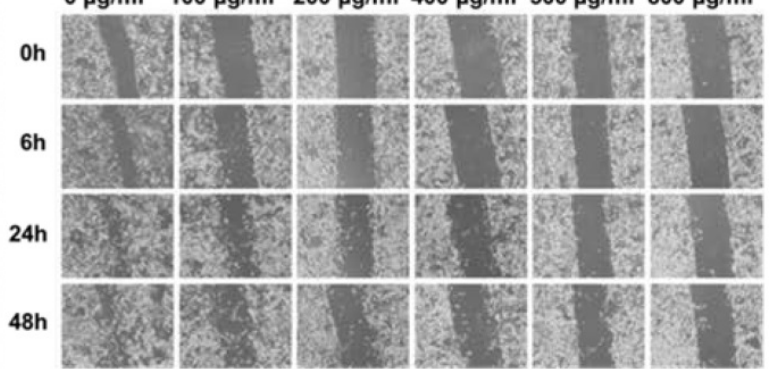

D.

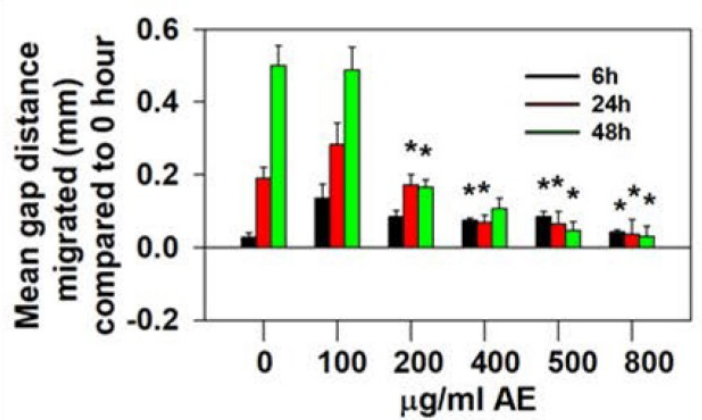

G. $0 \mu \mathrm{g} / \mathrm{ml} \quad 100 \mu \mathrm{g} / \mathrm{ml} 200 \mu \mathrm{g} / \mathrm{ml} 400 \mu \mathrm{g} / \mathrm{ml} \quad 500 \mu \mathrm{g} / \mathrm{ml} 800 \mu \mathrm{g} / \mathrm{ml}$

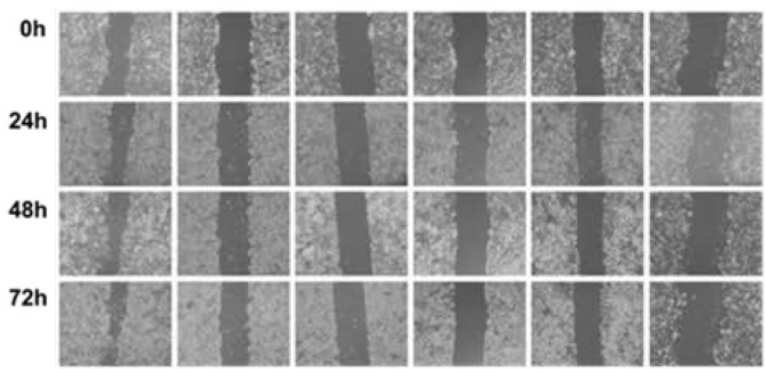

H.

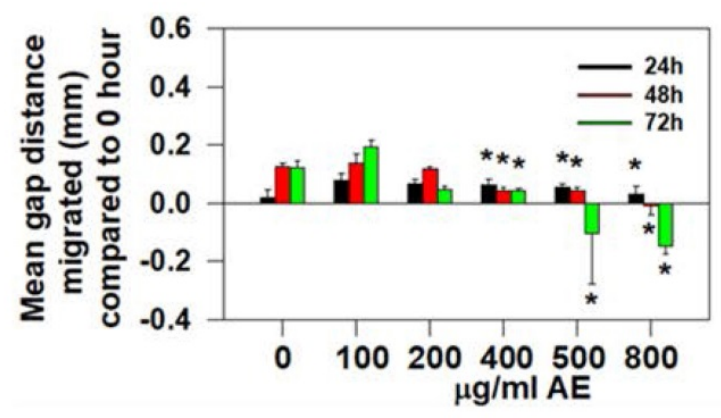

Figure 2. AE inhibited wound-healing by HGSOC cells in a time- and dose-dependent manner. (A-H) TOV3041, OV4453, OV866(2) and OV4485 cells were scratch-wounded at $90 \%$ confluency and treated with 100-800 $\mathrm{gg} / \mathrm{ml} \mathrm{AE}$ and further incubated for $48-72 \mathrm{~h}$. Gap distances were measured, normalized using an untreated control. (A, C, E) Representative images showing the inhibitory effect of AE on wound-healing migration of (A) TOV3041, (C) OV4453, and (E) OV866(2) cells captured at 0, 6, 24, and $48 \mathrm{~h}$. (G) Representative images showing the inhibitory effect of AE on wound-healing migration of OV 4485 cells captured at $0,24,48$ and 72 h. B, D, F and $\mathbf{H}$ Quantitative analysis of the results presented under (A, C, E, G). Results are shown as mean + S.E.M. from 6 independent experiments. *, P $\leq 0.05$ compared with 0 hour was considered significant. 
OV4485 cells appeared to be slow moving and migration was unaffected by all tested concentration of AE up to $24 \mathrm{~h}$ of incubation. At $48 \mathrm{~h}, 400 \mu \mathrm{g} / \mathrm{ml}$ $(\mathrm{P}=<0.02), 500 \mu \mathrm{g} / \mathrm{ml}$ and $800 \mu \mathrm{g} / \mathrm{ml}(\mathrm{P}=<0.001)$ of $\mathrm{AE}$ significantly inhibited migration. At $72 \mathrm{~h}, 400 \mu \mathrm{g} / \mathrm{ml}$ $(\mathrm{P}=<0.02), 500 \mu \mathrm{g} / \mathrm{ml}$ and $800 \mu \mathrm{g} / \mathrm{ml}(\mathrm{P}=<0.001)$ of $\mathrm{AE}$ inhibited migration significantly (Fig. 2G and $\mathbf{H}$ ).

OV866(2) cell line has been shown to have the highest anchorage-independent growth and cell invasion compared to the TOV3041G, OV4453 and OV4485 cell lines (13). Present results also show OV866(2) cells to have faster invasion rate compared to OV4485 cells and AE reduced invasion rate in both cell lines. These results suggest potential beneficial effect of AE for reducing tumor peritoneal metastasis and invasion. Malignant properties of all cell lines were attenuated by $\mathrm{AE}$ however; longer treatment with higher dose were required for more resistance cells (OV4485).

\section{AE down regulated the expression of HIF-1 $\alpha$ in HGSOC cells}

HIF-1a plays a significant role in invasion and metastasis of cancer cells and AE treatment attenuated invasion and metastatic properties of HGSOC cells, therefore, we determined the effect of $\mathrm{AE}$ on the expression of HIF-1a protein in all HGSOC cell lines.

AE treatment decreased HIF-1a immunostaining intensity and the number of immuno-positive cells $(\mathrm{P} \leq 001)$ (Fig. 3A-D). In addition, $\mathrm{AE}$ treatment in HGSOC cells significantly reduced HIF-1a protein levels as measured by Western blot analysis (Fig. 4A-D, HIF-1a panel and Fig. 4E). Our results show that expression of HIF-1a was significantly reduced in all HGSOC cells studied, however, OV4485 cells required higher dose of $\mathrm{AE}(500 \mu \mathrm{g} / \mathrm{ml})$ for significant reduction in HIF-1a expression.

\section{AE down regulated the expression of IGFIR in HGSOC cells}

IGF-1R is expressed at high levels on the surface of several types of cancer cells and its activation by IGF and/or hypoxia has been shown to cause cells to grow and divide [20] [21]. We studied the effect of AE on the expression of IGF1R protein in HGSOC cell lines. Both immunocytochemistry and Western blot results showed significant decrease in the expression of IGF-1R protein in all tested HGSOC cells. AE treatment decreased the intensity of IGF1R immuno-staining and the number of immuno-positive cells $(\mathrm{P}=0.001$, Fig. 3E-H). Western blot analysis also revealed significant inhibition of IGF-1R protein following $\mathrm{AE}$ treatment in TOV3041G $(\mathrm{P}=0.005)$, OV866(2) $(\mathrm{P}=0.002), \mathrm{OV} 4453(\mathrm{P}=0.007)$ and OV4485
$(\mathrm{P}=0.01)$ cells (Fig. 4A-D, IGF1R panel and Fig. 4F). These results suggest that $\mathrm{AE}$ down regulates angiogenesis in HGSOC cells as both HIF-1a and IGF1R are known to promote angiogenesis [4, 22].

\section{AE decreased the expression of metastasis-associated transcription factor SNAILI in HGSOC cells}

Hypoxia upregulates SNAIL1 in OC cells [23]. Therefore, we studied effect of $\mathrm{AE}$ treatment on SNAIL1 expression in HGSOC cells. Our results show a significant decrease $(\mathrm{P} \leq 0.001)$ in SNAIL1 protein expression in AE-treated HGSOC cells by immunostaining $(\mathrm{P} \leq 0.001)$ (Fig. 3I-L) and a significant decrease in SNAIL1 protein levels in TOV3041G $(\mathrm{P}=0.04), \mathrm{OV} 866(2) \quad(\mathrm{P}=0.03), \mathrm{OV} 4453 \quad(\mathrm{P}=0.01)$ and OV4485 $(\mathrm{P}=0.03)$ by Western blot analysis following AE treatment (Fig. 4A-D, SNAIL1 panel and Fig. 4G).

\section{AE upregulated the expression of E-cadherin in HGSOC cells}

Hypoxia attenuates E-cadherin expression via up-regulation of SNAIL in OC cells [24] where SNAIL1 is a direct repressor of E-cadherin, therefore, we studied the effect of $\mathrm{AE}$ treatment on E-cadherin protein expression in HGSOC cells. Our results show significant upregulation of E-cadherin expression $(\mathrm{P}=0.03$ to $\mathrm{P}<0.001)$ by immunostaining after $\mathrm{AE}$ treatment and an increase in E-cadherin protein levels by Western blot analysis in TOV3041G ( $\mathrm{P}=0.002)$, OV866(2) $(\mathrm{P}=0.01)$, OV4453 $(\mathrm{P}=0.002)$ and OV4485 $(\mathrm{P}=0.02)$ cells (Fig. 3M-3P and Fig. 4A-D, E-cadherin panel and Fig. $4 \mathbf{H}$ ). These results document that $\mathrm{AE}$ treatment modulates malignant properties of HGSOC cells through inhibition of SNAIL1 and activation of E-cadherin. Though Fleury et al did not detect E-cadherin in OV866(2) and OV4453 cells (13), present studies detected upregulation of E-cadherin following treatment with AE. Decreased expression of HIF-1 $\alpha$, IGF1R and SNAIL1 and increased expression of E-cadherin in these cells appeared to depend on the dose of AE. BRCA1 mutated cells required higher amounts of AE compared to other cells.

\section{AE inhibited tumor growth, HIF-1a, IGFIR, and SNAILI expression, but stimulated E-cadherin expression in HGSOC cell xenograft tumors in vivo}

We used mouse xenograft model to study in vivo effects of AE treatment. After 60 days of subcutaneous injection of OV4485 cells in nude mice, when tumors grew to form visible masses, animals were divided into untreated control group, and $\mathrm{AE}$ treated group $(\mathrm{N}=5$ mice/group). Mice in the untreated control group were fed $10 \%$ sucrose solution, whereas the 
treated group received $\mathrm{AE}$ in $10 \%$ sucrose solution for 28 days. Mice were sacrificed at 88 days after inoculation and tumors were excised.

As compared to untreated control group, $\mathrm{AE}$ treatment significantly decreased $(\mathrm{P}=0.02)$ tumor size (Fig. 5A-B) without obvious adverse effects. To confirm our in vitro findings, xenografts from untreated control and AE treated mice were examined for HIF-1a, IGF1R, SNAIL1 and E-cadherin protein expression. The number of HIF-1a ( $\mathrm{P}=0.006)$, IGF1R $(\mathrm{P}<0.001)$ and SNAIL1 $(\mathrm{P}=0.004)$ immuno-positive cells as percent of total number of cells was significantly reduced in AE treated group (Fig. 5C-H). The number of E-cadherin immunopositive cells was significantly increased $(\mathrm{P} \leq 0.001)$ in AE-treated group (Fig. 5I-5J).

Analysis of HIF-1a, IGF1R and SNAIL1 protein levels were decreased in AE-treated xenografts (Fig. 5-O panels HIF-1a, IGF1R, and SNAIL1 and Fig. 5P-R whereas intensity of E-cadherin protein band $(\mathrm{P} \leq 0.01)$ was significantly increased in AE-treated xenografts (Fig. 5O panel E-cadherin and 5S).

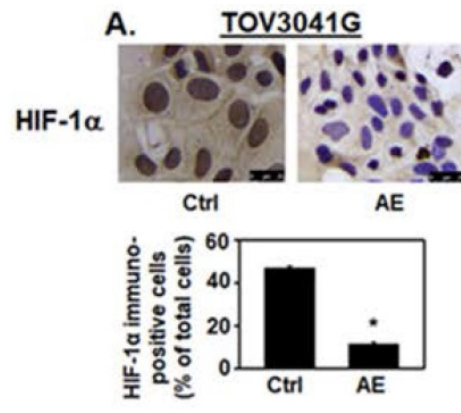

E.

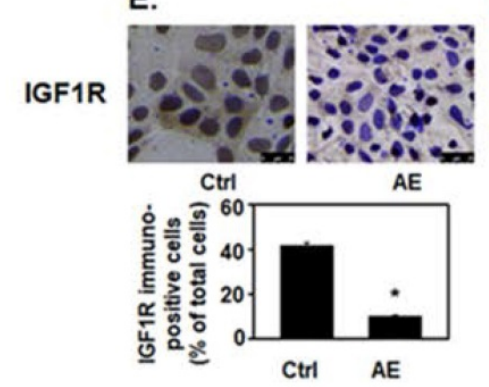

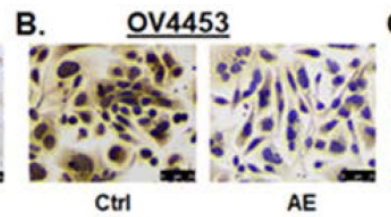

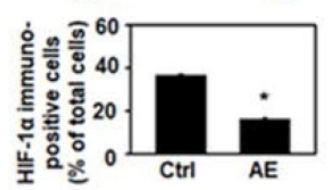

F.

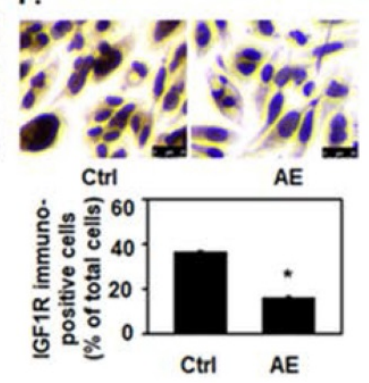

C. $\quad 0$ V866(2)
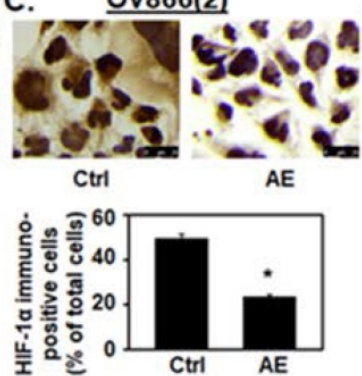

G.

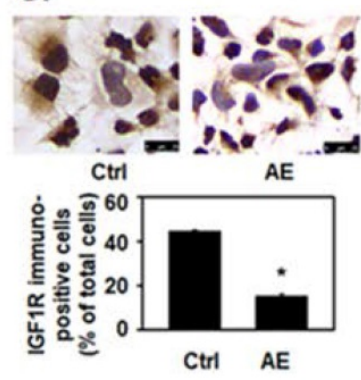

D.
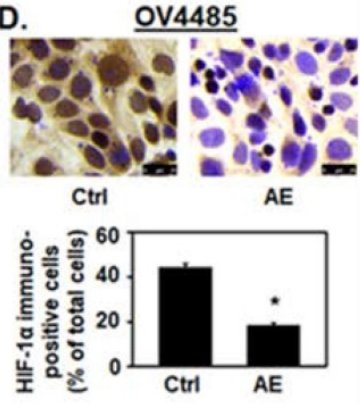

$\mathrm{H}$.

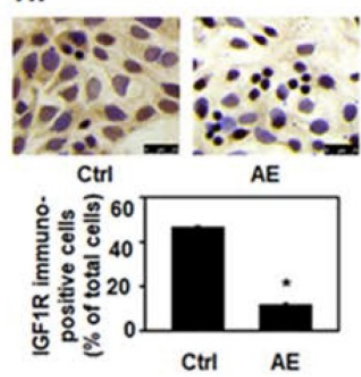

I.
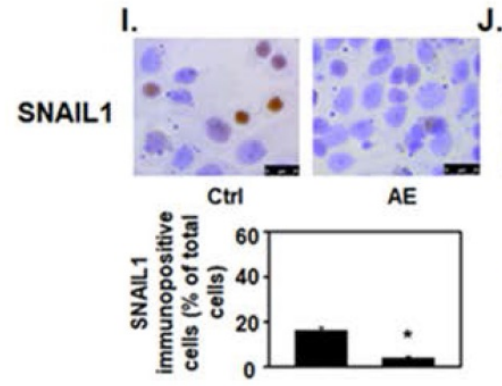

J.

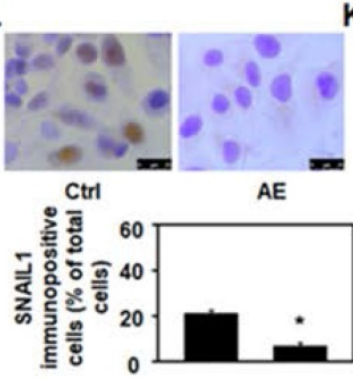

K.

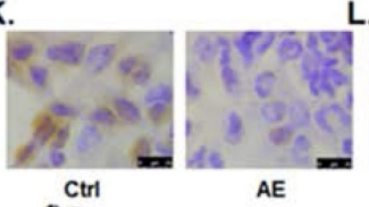

L.
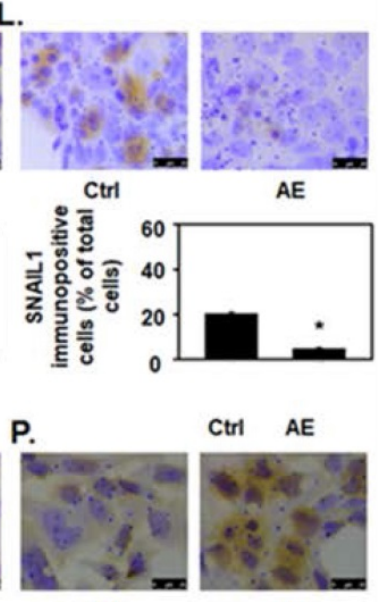

Ctri

AE

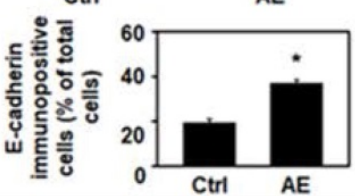

Figure 3. AE downregulates the expression of HIF-I $\alpha$, IGFIR, and SNAILI, and upregulates the expression of E-cadherin in HGSOC cells - (A, E, I, M) TOV3041G, (B, F, J, N) OV4453, (C, G, K, O) OV866(2) and (D, H, L, P) OV4485. Confluent cells were incubated with AE (400 $\mu$ g/ml for TOV3041G, OV4453, OV866(2) and $500 \mu \mathrm{g} / \mathrm{ml}$ OV4485) for 48 hours and analyzed using immunocytochemistry. Representative photomicrographs of 4 experiments are shown. Number immuno-stained cells were counted and calculated as percent of total cells. Results show decreased immuno-staining for HIF-1 $\alpha$ protein (A-D), (E-H) IGFIR protein and (I-L) SNAIL protein. In contrast immuno-staining for E-cadherin protein was increased (M-P). Results are presented as bar graphs showing Mean \pm SEM, *, P $\leq 0.05$ compared with control group. Bar=25 $\mu \mathrm{m}$. Ctrl=control, $\mathrm{AE}=$ Amla extract. 

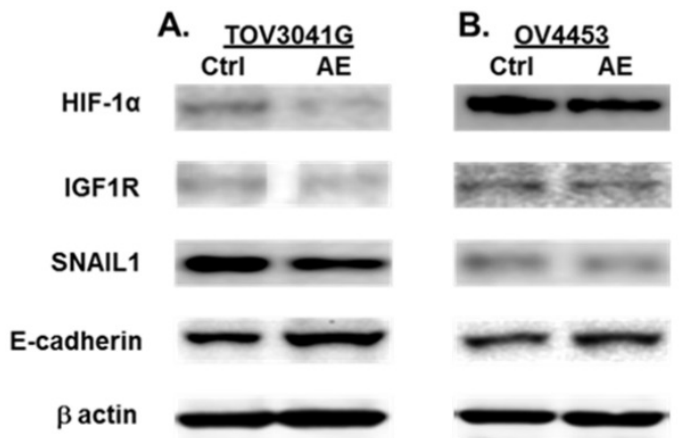

E.

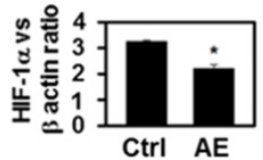

F.

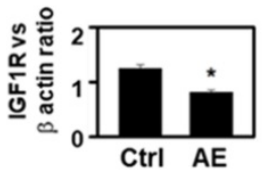

G.

H.
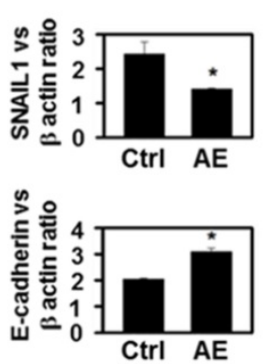
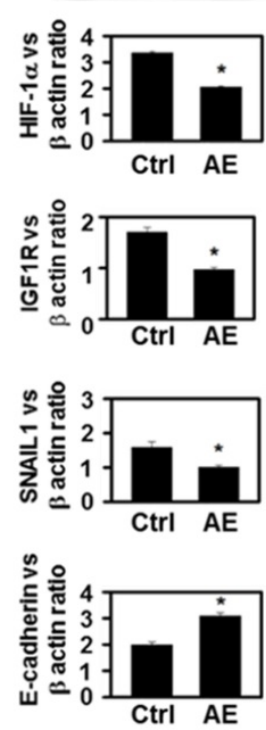
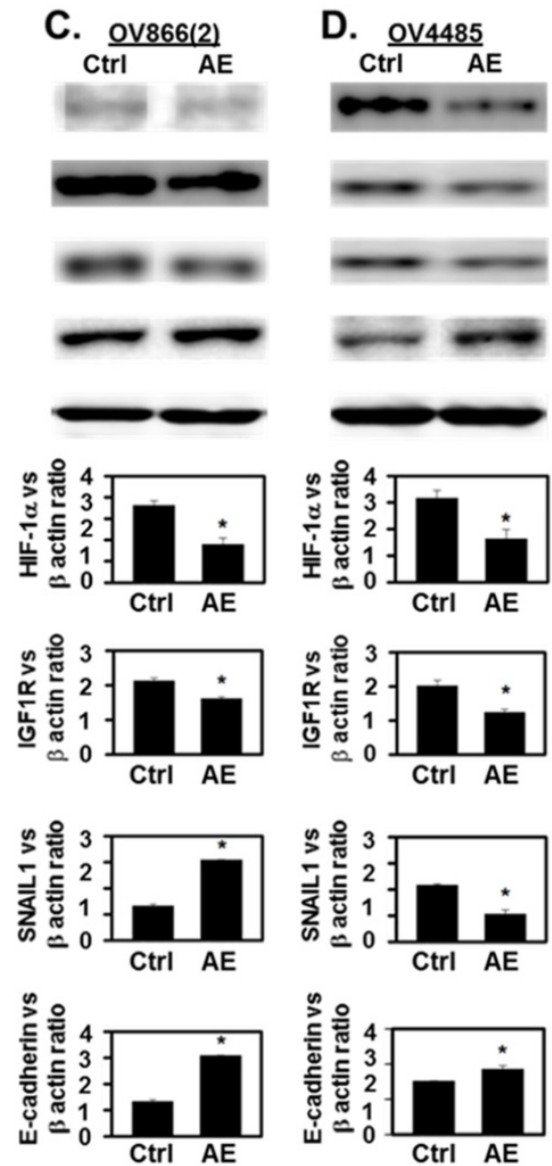

Figure 4. Incubation with AE downregulated the expression of HIF-I $\alpha$, IGFIR and SNAILI and increased the expression of E-cadherin in HGSOC cellsTOV3041G, OV4453, OV866(2) and OV4485. Confluent cells were incubated with AE for 48 hours and analyzed using SDS-PAGE and Western blotting as described. (A-D) Representative images in upper panels show that treatment with AE resulted in decreased expression of HIF-1 $\alpha$, IGFIR and SNAILI proteins. In contrast, AE-treated cells showed increased expression of E-cadherin protein. (E-H) Densitometry ratios of HIF-1 $\alpha / \beta$-actin, IGFIR/ $\beta$-actin, SNAIL1/ $\beta$-actin and E-cadherin/ $\beta$-actin. Results are presented

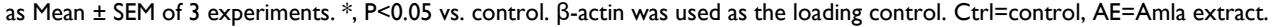

AE treatment significantly decreased $(\mathrm{P}=0.01)$ the number of Ki67 (a cellular marker for proliferation) [24] positive cells (Fig. 5K-L) suggesting that cell proliferation was inhibited in xenograft tumors of $\mathrm{AE}$ treatment compared to untreated control.

In addition, angiogenesis in xenograft tumor was studied by measuring tumor vascularization in tissue sections stained for CD31 - an endothelial marker. CD31 expression was significantly reduced in $\mathrm{AE}$ treated xenograft compared to controls (Fig. 5M). In addition, microvessel density was also significantly reduced $(\mathrm{P}=0.004)$ in xenografts tumors from $\mathrm{AE}$ treated mice (Fig. $5 \mathbf{N}$ ) as compared to untreated control.

\section{Discussion}

Results outlined above show that AE sensitized highly aggressive, resistant, metastatic HGSOC cells with or without mutations in p53, BRCA1/2 genes. $\mathrm{AE}$ treatment inhibited cell proliferation, migration and invasion properties of HGSOC cells. AE treatment also reduced the size of the xenograft tumor in mice developed from the most aggressive of the cell lines (OV4485) used. Our results show for the first time that AE treatment simultaneously inhibited cell growth and modulated key molecules of metastatic pathways (HIF-1a, IGF1R, SNAIL1 and IGF1R and E-cadherin) in resistant mutant HGSOC cells.

Key features of aggressive carcinomas including uncontrolled cell proliferation, migration, invasion and metastasis, are characterized by gene instability and impaired cellular signaling [25]. Spontaneous mutations in cancer cells can create phenotypically diverse populations of cells with varying mutations. Mutations including TP53, BRCA1, BRCA2, CSMD3 and RB1 are known to contribute to cancer cell migration, invasion and metastasis [26, 27]. The malignant and resistant nature of OC depends on phenotypically distinct sub-populations of cells with genomic instability and diverse mutations [28]. Previously we reported that AE treatment inhibits proliferation in OVCAR3 and SKOV3 cells. OVCAR3 cells express the R248Q mutant p53 and the SKOV3 is also a p53-mutant cell line which does not express p53 protein or mRNA [16, 17]. However, these cells 
are now considered to develop non-aggressive $\mathrm{OC}$ with diverse mutations [29]. Effect of AE treatment on heterogenous HGSOC is not known. Therefore, we selected four cell lines that have been characterized to reflect the heterogeneity of HGSOC. These included TOV3041G with no deleterious mutation, OV866(2) with TP53 mutation, OV4453 with TP53, BRCA2, CSMD3 and RB1 mutation, and OV4485 with TP53 and BRCA1 mutation. These cell lines were derived from samples collected at diagnosis or at the time of relapse, from either solid tissue (TOV) or ascites (OV) as described in Table 1 . The OV4453 cell line was derived from ascites from patients who had not received chemotherapy prior to surgery; whereas the OV866(2), TOV3041G and OV4485 cell lines were derived from samples obtained from recurring disease and thus the patients had been treated with chemotherapy before collection. OV4485 was reported to be the most aggressive among these cell lines. Results show that AE effectively inhibited growth, migration and invasiveness of heterogenous HGSOC cells. To further investigate the effect of AE on these HGSOC cells, we selected key molecules related to hypoxia, angiogenesis and EMT namely, HIF-1a, IGF1R, SNAIL1 and E-cadherin.
A.

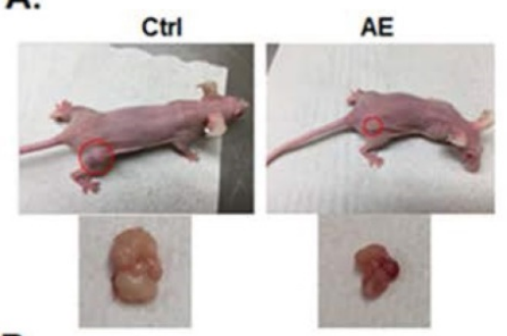

B.

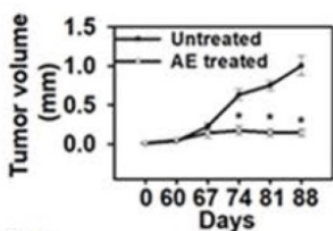

K. Ki67

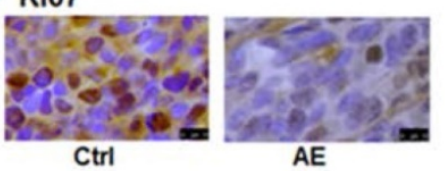

L.

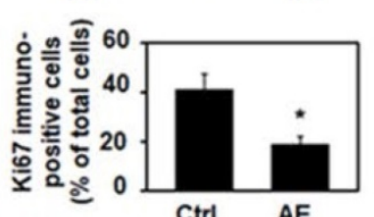

M.

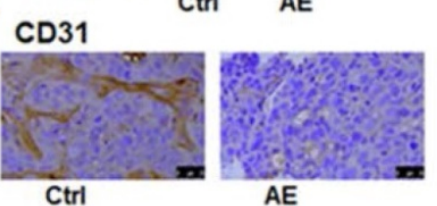

N.

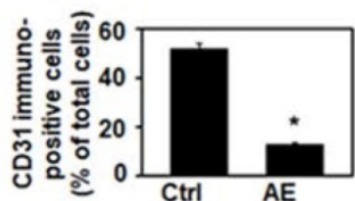

C.

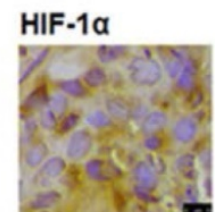

D.

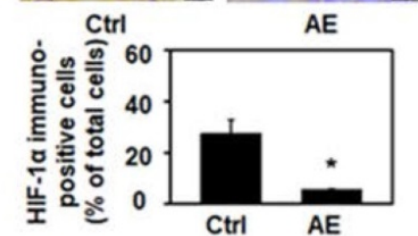

G.

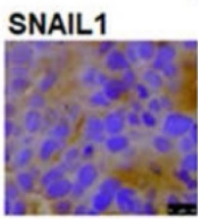

H.

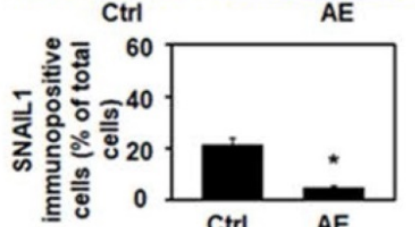

E.

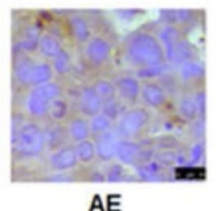

F.
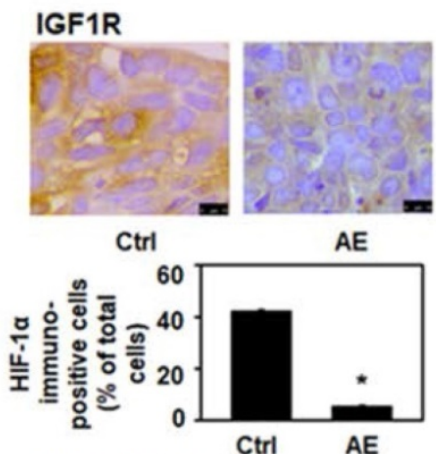

I.

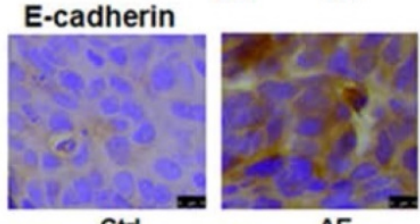

J.

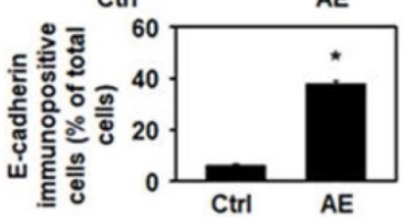

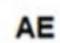

HIF-1a

IGF1R

SNAIL1

E-cadherin

B-actin

Ctrl
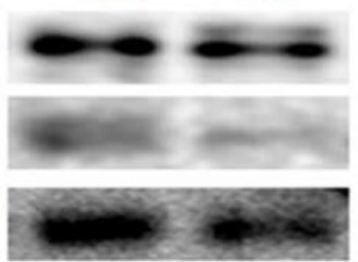

\section{P.}

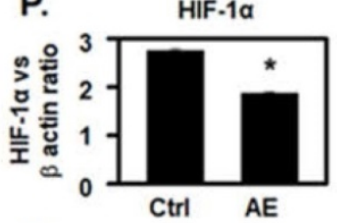

R.

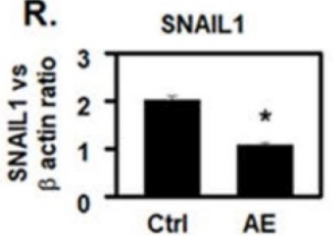

Q.

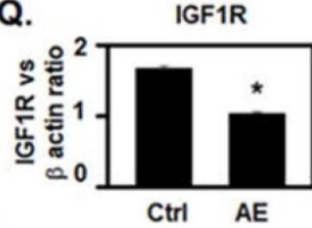

S.

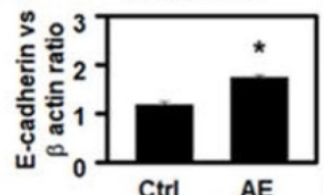

Figure 5. AE attenuated OV4485 xenograft tumor growth in athymic nude mice and downregulated HIF-I $\alpha$, IGFIR and SNAILI protein expression but upregulated E-cadherin protein expression. (A) Left upper: Untreated Nude mouse bearing tumors, left lower: tumor from untreated mouse (control), Right upper: $A E$ treated mouse. Right lower: tumor from AE-treated mouse. (B) Line graph showing change in tumor volume with time. Black line: untreated (control) tumor, Gray line: AE treated. (C-N) Immuno-histochemical analysis of xenograft tumor in untreated control and AE-treated mice. Results presented as bar graphs show immuno-positive cells as percent of total cell. (C-D) HIF-1 $\alpha$ expression was decreased by AE treatment. Bar=10 $\mu \mathrm{m}$. (E-F) IGF1R expression was decreased after AE treatment. Bar=10 $\mu \mathrm{m}$. (G-H) Decreased expression of SNAIL1 in xenograft tumors after AE treatment. Bar=10 $\mu \mathrm{m}$. (I-J) increased immuno-staining for E-cadherin in xenograft tumors after treatment with $A E$. Bar=10 $\mu$ m. (K-L) Decreased immuno-histochemical expression of Ki67 positive cells in mouse tumor xenograft after $A E$ treatment. Bar=10 $\mu$ m. (M-N) AE treatment decreased the immuno-histochemical expression of CD31 positive cells in mouse xenograft tumors Bar=25 $\mu \mathrm{m}$. (O) Representative Western blots showing a decreased expression of HIF-1 $\alpha$, IGF1R, SNAIL1 and increased expression of E-cadherin. $\beta$-actin was used as the loading control. (P-S) Western blotting results presented as densitometric ratios of, (P) HIF-1 $\alpha / \beta$-actin, (Q) IGFIR/ $\beta$-actin, (R) SNAIL1/ $\beta$-actin and (S) E-cadherin/ $\beta$-actin. All results were obtained using tumor tissues from 5 mice in each group. $V$ alues are Mean $\pm \mathrm{SEM}, *, \mathrm{P} \leq 0.05$ compared with control group. $C$ trl=control, AE=Amla extract. 
HIF-1a is involved in tumor cell proliferation, angiogenesis, metastasis, and chemotherapy resistance [6]. Overexpression of HIF-1a is observed in cells expressing wild type p53 and is associated with undifferentiated high-grade tumors that are refractory to treatment resulting in higher mortality rate. Overexpression of HIF-1a under normoxia increases p53 activity and, HIF-1a is essential for developing p53 mutant mouse model [30] [31]. p53 mutations accelerate cancer cell growth, poor differentiation, poor prognosis and resistance to treatment [32]. Both p53 and HIF-1 are mediators of cell adaptation to many stresses and are known to be involved in processes such as apoptosis, cell cycle control, and metabolism [33]. AE treatment attenuates oxidative damage-induced mutation and downregulates HIF-1a expression in OC cells [34] [16].

HIF-1a is overexpressed in BRCA1 and BRCA2 mutation carriers [35]. BRCA1 interacts with HIF-1a and regulates HIF-1a stability [36]. BRCA1 protein along with genetic and epigenetic changes of the BRCA1 gene is involved in the development of OC [37]. Our results show that $\mathrm{AE}$ treatment reduces HIF-1a expression in all tested HGSOC cell lines.

HIF-1a, p53 and BRCA1 closely interact with IGF1/ IGF1R signaling [21]. IGF1R expressed in malignant tumors plays a critical role in cell survival, invasion, metastasis, and angiogenesis [21]. IGF1R activation by IGF-1/IGF-2 induces HIF-1a and, both IGF1R and HIF-1a may simultaneously inhibit cell migration and invasion [38] [39]. IGF1R interacts with wild type p53 [21]. IGF1R levels are elevated in BRCA1-inactivated OC cells and BRCA1 knockdown activates IGF1R expression in non-BRCA1-mutated OC cells [40]. Results of the present study document that AE treatment downregulates IGF1R expression in all tested HGSOC cell lines.

IGF1/IGF1R signaling and HIF-1a regulate angiogenesis [21]. Results of the present study demonstrate that $\mathrm{AE}$ treatment suppresses expression of angiogenesis-related proteins namely, HIF-1a and IGF1R in HGSOC cells and, also in HGSOC derived xenograft tumor. This anti-angiogenic effect of $\mathrm{AE}$ treatment on HGSOC-derived xenograft tumor is further supported by results showing downregulation of angiogenesis marker CD31.

EMT is an early cellular process in cancer metastasis initiated by gene mutations. Mutation in p53 increases SNAIL1 protein expression and activity; and promotes EMT in many cancers [41]. SNAIL1 represses adhesion molecule E-cadherin and BRCA1 [42] [43]. SNAIL1 expression is high in low BRCA1 triple negative breast cancer [44]. Presently, AE inhibited SNAIL1 expression and upregulated E-cadherin expression in resistant heterogenous
HGSOC cells. We have previously reported similar effects of AE causing inhibition of growth and proliferation and angiogenesis and metastatic properties of OC in OVCAR3 and SKOV3 cells [29].

Currently OC are treated using a combination of approaches including chemotherapy agents, surgery and radiation. Ideas for treating cancer using multiple agents to target multiple molecules/pathways, for overcoming resistance and turning cancer into a manageable disease are being considered. Several plant-derived products provide an economical way to target multiple cancer molecules/pathways simultaneously $[45,46]$ to complement and enhance effectiveness of currently available treatment regimens. Flavonoids and alkaloids in plant extracts have been used to overcome drug resistance [47]. AE is known for antioxidant properties and contains many active components that might directly influence cellular processes at the gene level by increasing O-6-methylguanine-DNA methyltransferase activity that removes deleterious mutations in immune cells [14]. AE prevents chemical-induced DNA-damage in animal model. Our present results suggest a likely simultaneous effect of $\mathrm{AE}$ treatment on multiple cellular processes in $\mathrm{OC}$ through modulation of multiple targets.

\section{Conclusion}

Present study indicates for the first time an unmodified plant extract - AE treatment sensitizes highly resistant HGSOC cells and inhibits growth of these cells through modulation of key signaling molecules of angiogenesis and metastasis. AE, alone or in combination with currently used chemotherapeutic agents, may be an effective adjunct therapeutic agent for the treatment of resistant heterogenous HGSOC.

\section{Abbreviations}

AE: Amla (Emblica officinalis) extract; EMT: epithelial-to-mesenchymal transition; FBS: fetal bovine serum; HGSOC: high-grade serous ovarian cancers; HIF-1a: hypoxia-inducible factor 1a; IGF1R: insulin growth factor receptor 1; MTT: [3-(4,5-dimethylthiazol-2-yl)-2,5-diphenyltetrazolium bromide)]; OC: ovarian cancer; OSEM: ovarian surface epithelial Medium.

\section{Acknowledgements}

Authors wish to thank Dr. Anne-Marie Mes-Messon, Ph.D., Dept. of Medicine, Faculty of Medicine; Institut du cancer de Montréal, CRCHUM, University of Montréal., Montreal, Canada for the kind gift of cell lines used for these studies. 


\section{Funding}

This study was supported by the Kansas City VA Medical Center (KCVAMC) and Midwest Veterans Biomedical Research Foundation (MVBRF), Kansas City MO. This research was also supported in part from NIH-RO1 DK107490. KCVAMC, MVBRF and $\mathrm{NIH}$ did not have any role in the design of experiments, collection of data or in the interpretation of results.

\section{Competing Interests}

The authors have declared that no competing interest exists.

\section{References}

1. Kroeger PT, Drapkin R. Pathogenesis and heterogeneity of ovarian cancer. Current Opinion in Obstetrics \& Gynecology. 2017; 29: 26-34.

2. Ciucci A, Zannoni GF, Buttarelli M, Martinelli E, Mascilini F, Petrillo M, et al. Ovarian low and high grade serous carcinomas: hidden divergent features in the tumor microenvironment. Oncotarget. 2016; 7: 68033-43.

3. Lengyel E. Ovarian cancer development and metastasis. The American journal of pathology. 2010; 177: 1053-64.

4. Krock BL, Skuli N, Simon MC. Hypoxia-induced angiogenesis: good and evil. Genes \& cancer. 2011; 2: 1117-33

5. Horiuchi A, Hayashi T, Kikuchi N, Hayashi A, Fuseya C, Shiozawa T, et al. Hypoxia upregulates ovarian cancer invasiveness via the binding of HIF-1alpha to a hypoxia-induced, methylation-free hypoxia response element of S100A4 gene. International journal of cancer. 2012; 131: 1755-67.

6. Muz B, de la Puente P, Azab F, Azab AK. The role of hypoxia in cancer progression, angiogenesis, metastasis, and resistance to therapy. Hypoxia (Auckland, NZ). 2015; 3: 83-92.

7. Davidson B, Trope CG, Reich R. Epithelial-mesenchymal transition in ovarian carcinoma. Frontiers in oncology. 2012; 2: 33.

8. Wang YL, Zhao XM, Shuai ZF, Li CY, Bai QY, Yu XW, et al. Snail promotes epithelial-mesenchymal transition and invasiveness in human ovarian cancer cells. International journal of clinical and experimental medicine. 2015; 8: 7388-93.

9. Cancer Genome Atlas Research Network. Integrated genomic analyses of ovarian carcinoma. Nature. 2011; 474: 609-15

10. Bashashati A, Ha G, Tone A, Ding J, Prentice LM, Roth A, et al. Distinct evolutionary trajectories of primary high-grade serous ovarian cancers revealed through spatial mutational profiling. The Journal of pathology. 2013; 231: 21-34.

11. Fleury H, Communal L, Carmona E, Portelance L, Arcand SL, Rahimi K, et al. Novel high-grade serous epithelial ovarian cancer cell lines that reflect the molecular diversity of both the sporadic and hereditary disease. Genes \& cancer. 2015; 6: 378-98.

12. Gorringe $\mathrm{KL}$, George J, Anglesio MS, Ramakrishna M, Etemadmoghadam D, Cowin P, et al. Copy number analysis identifies novel interactions between genomic loci in ovarian cancer. PloS one. 2010; 5 .

13. Wojnarowicz PM, Oros KK, Quinn MC, Arcand SL, Gambaro K, Madore $\mathrm{J}$, et al. The genomic landscape of TP53 and p53 annotated high grade ovarian serous carcinomas from a defined founder population associated with patient outcome. PloS one. 2012; 7: e45484.

14. Baliga MS, Dsouza JJ. Amla (Emblica officinalis Gaertn), a wonder berry in the treatment and prevention of cancer. European journal of cancer prevention : the official journal of the European Cancer Prevention Organisation (ECP). 2011; 20: 225-39.

15. Sandra L. Gray S, SC (US); N., Dwight Camper C, SC (US) TUMOR AND MUTATION SUPPRESSING PLANT EXTRACT. US Clemson University Research Foundation, Anderson, SC (US) 2010.

16. De A, De A, Papasian C, Hentges S, Banerjee S, Haque I, et al. Emblica officinalis extract induces autophagy and inhibits human ovarian cancer cell proliferation, angiogenesis, growth of mouse xenograft tumors. PloS one. 2013; 8: e72748.

17. De A, Powers B, De A, Zhou J, Sharma S, Van Veldhuizen P, et al. Emblica officinalis extract downregulates pro-angiogenic molecules via upregulation of cellular and exosomal miR-375 in human ovarian cancer cells. Oncotarget. 2016; 7: 31484-500.
18. Bravo-Cordero JJ, Hodgson L, Condeelis J. Directed cell invasion and migration during metastasis. Current opinion in cell biology. 2012; 24: 277-83.

19. Weiswald LB, Bellet D, Dangles-Marie V. Spherical cancer models in tumor biology. Neoplasia (New York, NY). 2015; 17: 1-15.

20. Liu Q, Xu Z, Mao S, Chen W, Zeng R, Zhou S, et al. Effect of hypoxia on hypoxia inducible factor-1a, insulin-like growth factor I and vascular endothelial growth factor expression in hepatocellular carcinoma HepG2 cells. Oncology letters. 2015; 9: 1142-8.

21. Werner H, Sarfstein R, LeRoith D, Bruchim I. Insulin-like Growth Factor 1 Signaling Axis Meets p53 Genome Protection Pathways. Frontiers in oncology. 2016; 6: 159.

22. Bid HK, Zhan J, Phelps DA, Kurmasheva RT, Houghton PJ. Potent inhibition of angiogenesis by the IGF-1 receptor-targeting antibody SCH717454 is reversed by IGF-2. Molecular cancer therapeutics. 2012; 11: 649-59.

23. Qin J, Liu Y, Lu Y, Liu M, Li M, Li J, et al. Hypoxia-inducible factor 1 alpha promotes cancer stem cells-like properties in human ovarian cancer cells by upregulating SIRT1 expression. Scientific Reports. 2017; 7: 10592.

24. Imai T, Horiuchi A, Wang C, Oka K, Ohira S, Nikaido T, et al. Hypoxia attenuates the expression of E-cadherin via up-regulation of SNAIL in ovarian carcinoma cells. The American journal of pathology. 2003; 163: 1437-47.

25. Martin TA YL, Sanders AJ, Lane J, and Jiang WG. Madame Curie Bioscience Database [Internet] Austin (TX): Landes Bioscience. 2000-2013.

26. Muller PA, Vousden KH, Norman JC. p53 and its mutants in tumor cell migration and invasion. The Journal of cell biology. 2011; 192: 209-18.

27. Yasmeen A, Liu W, Dekhil H, Kassab A, Aloyz R, Foulkes WD, et al. BRCA1 mutations contribute to cell motility and invasion by affecting its main regulators. Cell cycle (Georgetown, Tex). 2008; 7: 3781-3.

28. Meacham CE, Morrison SJ. Tumour heterogeneity and cancer cell plasticity. Nature. 2013; 501: 328-37.

29. Domcke S, Sinha R, Levine DA, Sander C, Schultz N. Evaluating cell lines as tumour models by comparison of genomic profiles. Nature communications. 2013; 4: 2126.

30. An WG, Kanekal M, Simon MC, Maltepe E, Blagosklonny MV, Neckers LM. Stabilization of wild-type p53 by hypoxia-inducible factor 1alpha. Nature. 1998; 392: 405-8.

31. Bertout JA, Patel SA, Fryer BH, Durham AC, Covello KL, Olive KP, et al. Heterozygosity for hypoxia inducible factor 1alpha decreases the incidence of thymic lymphomas in a p53 mutant mouse model. Cancer research. 2009; 69: 3213-20.

32. Hientz K, Mohr A, Bhakta-Guha D, Efferth T. The role of p53 in cancer drug resistance and targeted chemotherapy. Oncotarget. 2017; 8: 8921-46.

33. Obacz J, Pastorekova S, Vojtesek B, Hrstka R. Cross-talk between HIF and p53 as mediators of molecular responses to physiological and genotoxic stresses. Molecular cancer. 2013; 12: 93

34. Zhao T, Sun $Q$, Marques M, Witcher M. Anticancer Properties of Phyllanthus emblica (Indian Gooseberry). Oxidative medicine and cellular longevity. 2015; 2015: 950890.

35. van der Groep P, van Diest PJ, Smolders YH, Ausems MG, van der Luijt RB, Menko FH, et al. HIF-1alpha overexpression in ductal carcinoma in situ of the breast in BRCA1 and BRCA2 mutation carriers. PloS one. 2013; 8: e56055.

36. Kang HJ, Kim HJ, Rih JK, Mattson TL, Kim KW, Cho CH, et al. BRCA1 plays a role in the hypoxic response by regulating HIF-1alpha stability and by modulating vascular endothelial growth factor expression. The Journal of biological chemistry. 2006; 281: 13047-56.

37. Wang C, Horiuchi A, Imai T, Ohira S, Itoh K, Nikaido T, et al. Expression of BRCA1 protein in benign, borderline, and malignant epithelial ovarian neoplasms and its relationship to methylation and allelic loss of the BRCA1 gene. The Journal of pathology. 2004: 202: 215-23.

38. Feldser D, Agani F, Iyer NV, Pak B, Ferreira G, Semenza GL. Reciprocal positive regulation of hypoxia-inducible factor 1alpha and insulin-like growth factor 2. Cancer research. 1999; 59: 3915-8

39. Mancini M, Gariboldi MB, Taiana E, Bonzi MC, Craparotta I, Pagin M, et al. Co-targeting the IGF system and HIF-1 inhibits migration and invasion by (triple-negative) breast cancer cells. British journal of cancer. 2014; 110: 2865-73.

40. Liu B, Li D, Guan YF. BRCA1 regulates insulin-like growth factor 1 receptor levels in ovarian cancer. Oncology letters. 2014; 7: 1733-7.

41. Roger L, Jullien L, Gire V, Roux P. Gain of oncogenic function of p53 mutants regulates E-cadherin expression uncoupled from cell invasion in colon cancer cells. Journal of cell science. 2010; 123: 1295-305.

42. Powell E, Piwnica-Worms D, Piwnica-Worms H. Contribution of p53 to metastasis. Cancer discovery. 2014; 4: 405-14. 
43. Wu ZQ, Li XY, Hu CY, Ford M, Kleer CG, Weiss SJ. Canonical Wnt signaling regulates Slug activity and links epithelial-mesenchymal transition with epigenetic Breast Cancer 1, Early Onset (BRCA1) repression. Proceedings of the National Academy of Sciences of the United States of America. 2012; 109: 16654-9.

44. Sengodan SK, K HS, Nadhan R, Srinivas P. Regulation of epithelial to mesenchymal transition by BRCA1 in breast cancer. Critical reviews in oncology/hematology. 2018; 123: 74-82.

45. Atanasov AG, Waltenberger B, Pferschy-Wenzig EM, Linder $T$, Wawrosch C, Uhrin $\mathrm{P}$, et al. Discovery and resupply of pharmacologically active plant-derived natural products: A review. Biotechnology advances. 2015; 33: 1582-614.

46. Bazrafshan N. LMM. A multi-objective multi-drug model for cancer chemotherapy treatment planning: A cost-effective approach to designing clinical trials. Computers \& Chemical Engineering. 2016; 87: 226-33.

47. Chandra H, Bishnoi P, Yadav A, Patni B, Mishra AP, Nautiyal AR. Antimicrobial Resistance and the Alternative Resources with Special Emphasis on Plant-Based Antimicrobials-A Review. Plants (Basel, Switzerland). 2017; 6 . 